\title{
Article
}

\section{Adding SPICE to a Library Intranet Site: A Recipe to Enhance Usability}

Lisa Cotter

School Librarian, Nursing and Midwifery

The University of Newcastle and Northern Sydney Central Coast Health

Gosford, NSW, Australia

E-mail: lisa.cotter@newcastle.edu.au

Larnich Harije

Technical Services Librarian, Central Coast Health Service Library,

Northern Sydney Central Coast Health

Gosford, NSW, Australia

E-mail: 1harije@nsccahs.health.nsw.gov.au

\section{Suzanne Lewis}

Manager, Central Coast Health Service Library

Northern Sydney Central Coast Health

Gosford, NSW, Australia

E-mail: slewis@nsccahs.health.nsw.gov.au

Ingrid Tonnison

Client Services Librarian, Central Coast Health Service Library,

Northern Sydney Central Coast Health

Gosford, NSW, Australia

E-mail: itonnison@nsccahs.health.nsw.gov.au

Received: 9 December 2005

Accepted: 6 March 2006

(C) 2006 Cotter, Harije, Lewis and Tonnison. This is an Open Access article distributed under the terms of the Creative Commons Attribution License (http://creativecommons.org/licenses/by/2.0), which permits unrestricted use, distribution, and reproduction in any medium, provided the original work is properly cited.

\begin{abstract}
Objective - To produce a highly-usable intranet site, use the project to explore the practical application of evidence-based librarianship (EBL), and refine the library's project management methodology.

Methods - Evidence was gathered via a literature review, an online survey, scenariobased usability testing, and completion of a usability checklist. Usability issues were then addressed, guided by the Research-Based Web Design and Usability Guidelines.
\end{abstract}


Results - After a preliminary revision, the site achieved a usability index of $79 \%$ after application of the "Raward Library Usability Analysis Tool". Finding the information and supporting user tasks were identified as areas of weakness. Usability testing and client feedback supported these findings. After these issues were addressed by a major site redevelopment, the usability index increased to $98 \%$.

Conclusions - Raward's checklist is an easy and effective tool for measuring and identifying usability issues. Its value was enhanced by scenario-based usability testing, which yielded rich, client-specific information. The application of EBL and project management principles enhanced the outcomes of the project, and the professional development of the project team.

\section{Objective}

The Central Coast Health Service (CCHS) Library in New South Wales, Australia, provides information services to meet the clinical, research and learning needs of the Central Coast sector (803 beds) of Northern Sydney Central Coast Health (NSCCH). The primary client groups include the CCHS staff (3665 FTE) and health students based at CCHS. The main site, Gosford Hospital, is a teaching hospital of The University of Newcastle, Australia. This partnership in health education and training has been particularly successful in the area of library services, with a strong, mutually beneficial relationship maintained between the CCHS Library and The University of Newcastle Library.

In May 2003, librarians from the CCHS Library were introduced to the evidence based librarianship (EBL) framework via a course offered through the National electronic Library for Health (NeLH) (Booth "Briefing"). Following an exercise which asked participants to identify an aspect of current service provision that was based on poor evidence, the CCHS librarians acknowledged that the Library's intranet site was a service based on very poor evidence, and had outgrown its original structure and purpose. The following year, a project team was established to thoroughly revise both the architecture and content of the site, with a focus on improving usability. Members of the team included the Client Services Librarian, Technical Services Librarian, University Liaison Librarian, and the Library Manager.
The objectives of the project were to produce a highly usable library intranet site; to undertake the project as an opportunity to explore the practice of EBL; and to use the project as a means of refining the library's newly-adopted project management methodology. Accordingly, the problem - a userunfriendly intranet site - was reframed in terms of the following research question:

"How can the usability of the CCHS Library's intranet site be improved to enhance the site's effectiveness as a gateway to the Library's services and resources, for the staff and students of the organisation?"

The primary objective - to produce a highly usable intranet site - had to be achieved within the framework of an existing organisational template which restricted the modification of many design elements. Organisational culture was another issue as Central Coast Health was in the process of merging with a neighbouring health service. At the time of this writing, a combined, area-wide intranet is being developed. This project also provided an ideal opportunity to achieve the secondary objectives of exploring the practice of EBL, and refining the library's project management methodology. The team envisaged synergies between EBL and project management and planned to explore this idea as a potential tool for bridging the theory-practice gap. 


\section{Method}

The library's project methodology, based on the Project Management Body of Knowledge (A Guide), was used to plan the redevelopment of the library's intranet site. The methodology was enhanced by incorporating the principles of evidence based librarianship. To effectively assimilate the EBL process into the project plan, a series of workshops were scheduled to develop the team's understanding of the theory, and to explore its potential for integration into practice. The program included six journal club sessions structured around the EBL process, and used the library's current projects (Carter and Grimmond; Cotter et al.) as case studies throughout the series. Project team members were responsible for preparing and presenting one session each. An introductory overview session was followed by five workshops examining each stage of the EBL process in turn.

After a research question was framed, librarian-observed, user-reported, and research-derived evidence was gathered and appraised (Booth "Exceeding"). Findings were applied to the project in varying degrees directly, by derivation, conditionally, or just by providing enlightenment (Booth "What"). Finally, the project outcomes were evaluated and disseminated. Like the phases of a project plan, the main processes of EBL are not necessarily independent and consecutive activities. They are inter-related, interdependent, and can occur concurrently.

The main phases of the project were to:

- Undertake a preliminary revision of the site to eliminate incorrect, obsolete, unnecessary, and poorly presented pages. This provided a suitable starting point from which further evidence-based improvements could be made.

- Locate, retrieve, and examine the evidence to identify required modifications. The evidence was taken from the literature, usability testing, and feedback from library staff and clients.

- Implement the recommended changes, and publish the redeveloped and now highly-usable intranet site.

- Define guidelines for the ongoing maintenance and development of the site.

- Evaluate the new intranet site and the project team's utilisation of EBL.

- Disseminate the results via a launch of the new site, presentation of a hot topic at the $3^{\text {rd }}$ International Evidence Based Librarianship Conference, and publication of the project report

\section{Refining the Question}

The SPICE anatomy (Booth "Formulating" 6566) was used to focus the direction of the project and refine the research question (Table 1):

\begin{tabular}{|lll|}
\hline S & Setting & CCHS Library intranet site \\
P & Perspective & $\begin{array}{l}\text { Staff and students of the organisation } \\
\text { Gateway to our services E resources }\end{array}$ \\
I & Intervention & Site improvements \\
C & Comparison & Original site \\
E & Evaluation & Usability (as a determiner of effectiveness)
\end{tabular}

Table 1. SPICE breakdown 
Asking a clear and answerable question at the start of the project was vital to its successful completion. One well-formulated question had been developed to focus the project's scope, but additional questions were needed, particularly at the literature review stage. The literature review became problematic because the project team attempted to use one search strategy to answer several different questions such as "What makes a good intranet site?" and "How do you conduct usability testing?"

\section{Literature Review}

Preliminary searching revealed a large amount of literature on design and evaluation of Internet/intranet sites. Initially, the research question used the terms usability and effectiveness interchangeably. The review clarified the distinctions between these two terms and related terms such as usefulness. This awareness led to the original question being focussed to specify usability as the evaluation measure, thereby limiting the number of potential evaluation tools that would require examination.

A search strategy was designed, with inclusion and exclusion criteria. Databases covering the literature of library \& information science (LISA, ALISA, Library Literature, APAIS/APAFT, Emerald Library), health (MEDLINE, CINAHL, EMBASE, AustHealth), and technology (Gartner Core Research, IEEEXplore) were selected. Several multidisciplinary databases (Proquest 5000, Expanded Academic Index, Megafile Premier, Blackwell Synergy, ScienceDirect) were also used. The Internet was also searched. The project team considered it an appropriate source since many organisations publish their usability studies on their websites (Campbell et al.; Clairmont, Dickstein and Mills; MIT Libraries). A few core texts provided background information (Krug; Norlin). Responsibility for searching was divided among the project team. One team member aggregated the individual summaries into a documented literature review allowing the team's individual efforts to be considered as a whole.
The main themes to emerge from the literature review were: distinctions between usefulness, effectiveness, and usability; usability testing in practice; and web design guidelines.

Various definitions of usability were identified, the most useful version provided by the International Organization for Standardization (ISO 13407): “The usability of an interface is a measure of the effectiveness, efficiency and satisfaction with which specified users can achieve specified goals in a particular environment with that interface". The project plan acknowledges that usability is only one indicator of the overall effectiveness of an intranet site, and that other components, such as accessibility and the extent to which clients needs are being met, also contribute to effectiveness. Such factors, however, are beyond the scope of this project.

Usability testing "does not tell you who is actually using your web-based services, whether their needs are being met, or whether you are reaching your target clientele" (Pearce 20).This is directly applicable to the present study, as the project team were only testing the existing content of the site, not resources or services that potentially could be included. Also, the research participants were all users of the organisation's intranet site at the time of their participation, so the project was not reaching non-users, or potential users, nor identifying barriers to use.

The literature search yielded a large number of resources describing practical approaches to usability testing. MIT Libraries' Web Site Usability Test, and an entire issue of Library Technology Reports on usability testing (Pace) were particularly helpful. They provided practical guidance in carrying out usability testing under real-life conditions and included examples of test protocols, sample questions, and data recording sheets. Steve Krug's book Don't Make Me Think! was useful in providing details on how to administer the usability sessions, including a sample script for the testers to use, room setup, and how to interact with the subjects of the study. 
As well as such case reports, numerous guidelines and lists of recommendations were uncovered, with varying strengths of evidence and degrees of applicability. Much of the literature deals with commercial websites, but libraries and intranet sites may have a different focus (Pace 35). Critical appraisal resulted in two instruments being selected for use in this project. They were Research-Based Web Design and Usability Guidelines (Koyani, Bailey and Nall) which includes 187 recommendations underpinned by research, with each carrying a strength of evidence, and a relative importance score; and the "Raward Library Usability Analysis Tool" (Raward, "Study" 226-30), which is a best practice checklist for the design of library websites intended to be a cost-effective way to conduct, user-centred studies without user involvement (Raward, "Report").

Results of the literature review were appraised for validity, reliability, and applicability; yet, the team concede that "intrinsic factors that relate to research design and aspects of methodology" (Booth and Brice 105) were only appraised superficially. Use of appraisal tools, such as the CriSTAL checklists (Booth, "CriSTAL"), would have allowed critical assessment of the intrinsic factors.

\section{Client Feedback}

An e-mail sent organisation-wide, together with a link prominently displayed on the library's intranet home page, invited feedback and suggestions via a simple online survey. The objective of the survey was to establish the use which was actually being made of the intranet site, and to reveal the client perspective of the functions the site should be performing. The survey asked:

- Is the library intranet site easy to use?

- What are your main reasons for using the library site?

- What would you like to use the library site for?

- Would you use links to selected Internet sites for your speciality?
The intent of the survey was to ensure the project goals and client needs were aligned in order to avoid the pitfall of "broccoli librarianship" - librarians imposing on clients what they should do because that is what is good for them (Vaughn and Callicott). In conjunction with observations made by library staff, results of the survey were used to compile a list of the major functions the library intranet site was expected to perform. A further function of the survey was to enlist volunteers to take part in the scenario-based usability testing of the site.

Qualitative data which represented client feelings about the usability of the site was elicited via questions posed during a post-test discussion (see Appendix A). Capturing participant views immediately after they used the site to perform scenario-based tasks enhanced the quality of the responses. The post-test discussion was used in lieu of focus groups as the project team was unable to recruit volunteers from busy clinical areas for focus groups.

Client feedback from the online survey and post-test discussions was appraised for validity and contextual relevance.

\section{Usability Testing}

Usability testing was undertaken in two forms. The Raward usability checklist was applied to the intranet site by individual members of the project team to identify how the site fell short of recognised best practice for usability. Library clients performed scenario-based tasks while under observation to provide a usability assessment based on specific, local needs and use of the site.

\section{Checklist analysis}

The "Raward Library Usability Analysis Tool" (Raward, "Study" 226-30) was applied to the library's intranet site before and after a preliminary revision of the site based only on the project team's professional judgement. The Raward checklist was next applied to the site after its major redesign at the end of 2005 (the current site), with the intention of applying it 
at each major revision of the site. This tool, a 103 question checklist, is the result of an Australian librarian's research project which examined the usability of library websites. Although the tool was developed specifically for academic library websites, it was deemed applicable for this project on the basis that it was designed for non-commercial, serviceoriented organisations. Each time the tool was used, at least two independent evaluators applied it to the intranet site and results were compared.

\section{Scenario- Based Tasks}

Scenario-based usability testing of the library's intranet site was based upon the fourteen main functions of the site derived from the survey.

In response to a challenge made to librarians who conduct usability testing to consider the role of a library's website in relation to the library itself (Vaughn and Callicott 16), the project team determined that the library's intranet site assumed both the roles of a substitution for and an extension of the physical library. Vaughn \& Callicott argue that, if the site is regarded as a substitute for the library, then the usability test instrument should not contain any hints for the users, for example, a simple statement such as "Databases allow you to search for articles on various topics". Without such hints, the usability test will test ease of use. If the site is seen as an extension of the library, then minimal instructional statements should be included in the test instrument and the focus of the test will change to usefulness. In both cases, the tasks posed must be sure to test the usability of the site, and not the information literacy skill of the participant.

The substitution/extension approach becomes problematic when the site has to fill both roles. The CCHS Library is part of a 24/7 organisation. When the library is open, the intranet site functions as an extension of the library, but when the library is closed, some parts of the organisation (inpatient wards, Emergency Department) continue to function and rely on the intranet site as a substitute for the library. Throughout the testing process, this was one issue which was not satisfactorily resolved. However, formation of the scenariobased tasks - meant to reflect real-life use of the site - tended towards testing ease of use. The scenarios posed in this usability study are included as Appendix B.

Clients who completed the online survey and indicated on the survey form their willingness to participate in the scenario-based testing sessions were contacted to organise session times. Renowned usability expert Jakob Nielsen states that "the best results come from testing no more than 5 users and running as many small tests as you can afford" (Nielsen). According to Nielsen, a usability study with five subjects will identify $85 \%$ of a site's usability problems. More users would be required if highly distinctive user groups are being represented, in which case, three to four from each group should be selected. On this recommendation, the project team, which plans to undertake a round of usability testing at each stage of the intranet redevelopment, will conduct in each round two tests of seven scenarios with participants representing the intranet's major client groups - hospital staff (clinical and administrative) and university students. Each volunteer will only be eligible to participate in one round of testing, but the participant profile at each round will be consistent.

At the time of this writing, the first round of testing has been completed. Eight hospital staff members, representing the clinical and administrative client groups, participated. Students were excluded from the first round of usability testing on the basis that the site was not yet a seamless interface for the two distinct client groups. Testing seamlessness at this early stage of the project would not have yielded useful results. The first round of revisions addressed this problem and so the next round of usability testing will examine the impact of these changes by including students in the participant cohort.

The scenario-based usability test sessions were run by two members of the project team: one as administrator, and one as recorder. The 
administrator welcomed the volunteer, administered the participant profile questionnaire, conducted the scenarios, and facilitated the post-test discussion (see Appendices C, B and A). The recorder had minimal interaction with both the volunteers and the administrator and, instead, concentrated on the documentation of the sessions on recording sheets (see Appendix D). For each scenario there was a recording sheet which set out the preferred navigation path. The recorder ticked off each step and noted any variation, as the volunteer moved through the intranet site. Other details recorded included the number of clicks needed to complete the scenario, whether the volunteer was successful or unsuccessful in completing the scenario and any problems of navigation, architecture, content, terminology, presentation, search tool, or user support which were encountered. The administrator kept a separate record (see Appendix E) and each session was audio-taped. Screen capture software would have been ideal for recording the usability test sessions. Unfortunately, the project team did not have access to the necessary equipment or budget required to purchase it. In order to obtain the most accurate record of the session possible, the administrator and recorder reviewed each session immediately after the volunteer left and combined notes (see Appendix F).

Usability testing was conducted in the library rather than on the wards, which would have better emulated real-life use of the site. Testing in the library was a practical necessity due to the difficulties of computer access and the interruptions which would be expected to occur in the busy clinical workplace.

Results of the scenario-based usability testing were appraised for validity by examining the actual responses of the participants to each scenario against the information the project team expected to gain from each scenario. The methodology was also appraised for reliability. For example, there was some inconsistency in the way in which the scenario-based test sessions were administered and recorded by the project team. Also, the project team were administering the tests largely to participants known to them, and were also responsible for redesigning the intranet site, and therefore some bias in the results was inevitable.

\section{Research Based Guidelines}

Once usability issues had been identified, the usability checklist applied, and the scenariobased usability testing conducted, ResearchBased Web Design \& Usability Guidelines (Koyani, Bailey and Nall) was referred to for evidence based solutions. Each guideline in this document includes "a brief statement of the overarching principle that is the foundation of the guideline, further explanatory comments on the research, graphic examples of the guideline in practice and citations to relevant websites, technical and research reports supporting the guideline" (Booth, "Untangling" 71). To assist in the process of applying the recommendations locally, each guideline is assigned a strength of evidence and relative importance score.

Once relevant guidelines were identified, they were applied, taking into account local conditions such as a fixed intranet template and organisational structure and culture.

\section{Results}

Raward's checklist was an effective way to identify where the site fell short of best practice in design for usability. Keevil explains that usability checklists "can measure the usability index of a website and determine, expressed as a percentage, how closely the features of a particular website match generally accepted usability guidelines" (qtd. in Raward, "Study" 109). Not only can the usability scores of versions of the site be compared, but also, by virtue of the characteristics marked NO, a list of recommendations to improve usability can be extracted. The checklist identified several aspects of the site which needed attention, and this method alone would have resulted in a revised site with significantly enhanced usability. 


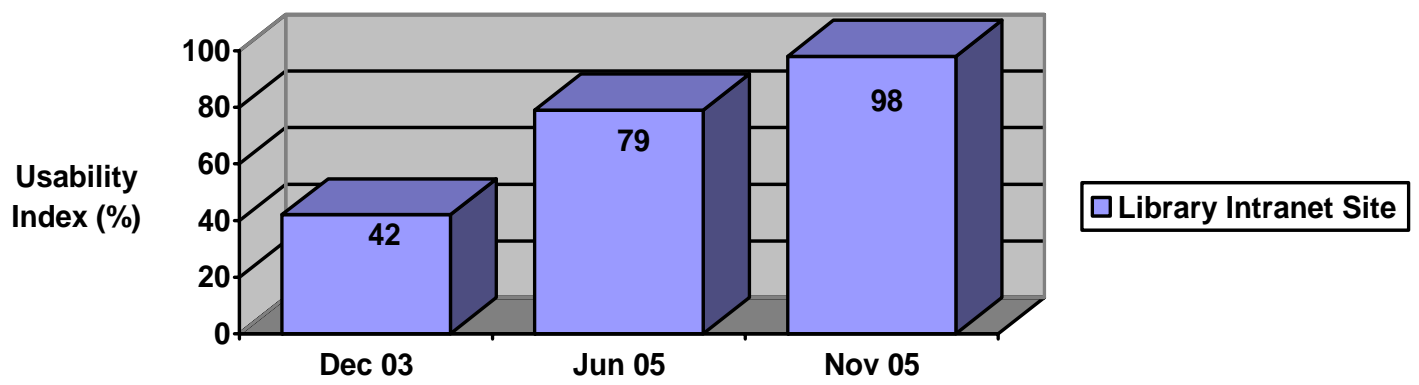

Figure 1. Raward Library Usability Index

When the checklist was applied to the original site (an archived version as at December 2003), it recorded a usability index of only $42 \%$. After the initial revision based only upon professional judgement (June 2005), the usability index improved considerably, achieving $79 \%$. When the site was substantially redesigned in November 2005 to address the issues identified by the usability study, the score again improved, this time to $98 \%$ (Figure $1)$.

The results of the scenario-based usability testing demonstrated a fairly usable site, though one with plenty of room for improvement. Overall, participants were able to successfully complete the tasks $87 \%$ of the time, but only $60 \%$ of the time by the preferred path. Scenario-based testing supported the findings of the usability checklist and had the added benefit of allowing the project team to observe how clients used the site to satisfy particular information needs. Not only were problems with the site identified, but some insight into why the problem existed was also gained. Valuable feedback on other library services and a positive public relations exercise were unforeseen benefits.

Analysis of the library intranet site using Raward's checklist showed that the site was strong in the areas of technical accuracy and providing information that is easy to understand; less strong in presenting information (including navigation and formatting); and relatively weak in supporting user tasks (including an index, site map, help screens, and FAQs). Usability testing supported these findings by pinpointing specific functions that clients expected to be able to carry out using the intranet site, but which were difficult in practice. As a result, the following major changes were made to the CCHS Library intranet site:

- inclusion of a site index

- phone, fax and, postal address included on home page

- details for contacting library staff included on each page

- commonly-used links made available on each page

- a link to the home page added to each page

- headings and links made jargon-free and task-based ("Renew Loans" replaced "MyLibrary")

- "Online Resources" page redesigned to group related elements together

- provision of an A-Z list of electronic journals

- hyperlink labels synonymous with their destination page titles

- images no longer used to represent hyperlinks

The redesign includes a new look, presentation, and format, and the site has been formally launched. A second round of usability testing is scheduled for early 2006. 


\section{Discussion}

Usability testing lies within the ambit of evidence based librarianship in that it is practical, grounded testing carried out in order to obtain evidence with which to address relevant and answerable questions facing the practice of librarianship.

Usability testing is part of a continuous cycle of development, implementation, and evaluation. EBL is based on a cyclical process of evaluation and improvement, and was, therefore, a suitable framework for this project. Although standard project methodologies emphasise formal closure of the project as a final stage, an ongoing program of usability testing would transcend the project lifecycle and become a part of the ongoing maintenance and development of the site.

The methodology used to enhance the usability of this library intranet site would be just as applicable to a usability study of other library Internet/intranet sites. It is anticipated that the findings of the project will be used to propose the launch of an Internet site for the CCHS Library.

With usability addressed, future projects could examine how to enhance other factors that contribute to the library site's effectiveness. Is the site meeting the needs of clients? Is the site accessible by clients? Do the potential users of the site have the skills necessary to use the resources provided? If such investigation leads to further revision of the site, modifications would be subject to usability testing, as a matter of course.

\section{Usability Testing}

The Raward Library Usability Analysis Tool was extremely valuable in the early stages of site development, promoting adoption of recognised best practice. Ongoing regular use of the checklist is limited by the subjectivity of certain sections of the assessment. However, it remains an extremely useful tool for maintaining a focus on best practice guidelines.

The project team found that, despite requiring a large investment of time, scenario-based testing yielded valuable information about the library's intranet site and exposed usability issues obscured by the limitations of the checklist analysis. The next round of scenariobased testing is expected to demonstrate that the usability index of $98 \%$ scored in November 2005 is an artificially high indicator of usability.

Applying Raward's checklist to the intranet site required a much smaller commitment of time and effort than conducting scenario-based testing. Writing the scenarios, scripts, and test protocol; making appointments with subjects; setting up the room; administering the tests; analysing the results; and so on, consumed large amounts of time. Conducting research as a team makes it a challenge to ensure consistency. Procedures for administration of the tests and recording of data were standardised, but variations still occurred. In contrast, each time Raward's checklist was applied to the intranet site (December 2003, June 2005, November 2005), two or more members of the project team applied the checklist independently of each other but obtained almost identical results. This confirmed the tool's suitability for the purpose for which it was designed - a quick and easy test of website usability requiring only a sole evaluator.

The Raward checklist and scenario-based testing were found to be complementary tools for identifying usability issues. To maximise the benefit of scenario-based testing (especially because it is so resource intensive), the methodology used here could be improved by implementing the changes recommended by Raward's best-practice guidelines, first. This would avoid scenario-based test subjects experiencing problems with usability, which could have been easily identified and resolved in the first instance, thereby maximising the project team's opportunity to gather valuable local, client-specific feedback.

This project did not test enough subjects to enable each usability objective (such as the time taken to complete a task, number of clicks, or completion via the preferred pathway) to be measured to a particular confidence level. To 
do so was beyond the resources of the project team. However, enough subjects (eight in total) were tested to obtain meaningful results for this type of research. It was the experience of the project team that after the first two or three usability tests, the subjects tended to identify the same problems and experience very similar difficulties with the site. For example, none of the subjects were able to successfully complete Scenario 4 (renewing loans online) due to the absence of a link for this function on the home page as well as unclear instructions for its use if/when the link was located.

\section{Application of EBL}

A project such as this cannot be achieved in isolation from the normal operation and management of the library. The project team undertook the usability study, not only as a means of improving the library's intranet site but also "to explore the realities and practicalities of the EBLIP process within the constraints offered by a library practitioner role" (Booth, "Australian" 71).

CCHS Library staff developed a strong understanding of EBL and its practical application over the course of this project largely due to the workshop series, prepared and presented by the project team.

One barrier to the EBL approach was that the project team did not have easy access to major library and information science databases with international coverage, e.g., Library and Information Science Abstracts (LISA) and Library Literature. Access to the indexed professional literature is required for EBL to make the transition from theory to practice. The project has also highlighted the difficulties of applying EBL when tools such as appraisal checklists are still under development or difficult to locate.

Following through all the stages presented by the EBL model, rather than just engaging with specific components, not only enhanced project outcomes but also enriched the professional development experience. For instance, project evaluation normally marks the end of a project. However, the EBL model encourages dissemination of results as a final stage, to enhance the evidence base available to the profession for future decision making. Knowledge that the project would be presented to an audience of peers, made the project team more rigorous at every stage from designing methodology to analysing results.

\section{Project Management}

The experience of the project team has been that project management and EBL are complementary and can enhance the outcomes of any project. EBL was identified as a way of ensuring best practice; project management ensures it is achieved efficiently. Just as flavour is enhanced by adding spice when cooking, embedding EBL in a project's methodology should produce a blueprint to enable a good project to become even better.

The usability project has demonstrated that EBL is not a "bolt-on extra" but "can be integrated within the accepted structure of the project management cycle" (Booth, "Australian" 71). The CCHS Library's standard project methodology has been refined to allow for the EBL model to be incorporated locally on an ongoing basis. The project team is now developing this project planning tool for wider application. It is anticipated that provision of such an instrument will help to bridge the gap between evidence based librarianship as a theory presented in a text book, and evidence based librarianship routinely applied in the workplace to enhance decision making.

\section{Acknowledgement}

A version of this paper was presented at the $3^{\text {rd }}$ International Evidence Based Librarianship Conference, held in Brisbane, Australia (October 2005). See: $<$ http://conferences.alia.org.au/ebl2005/Cotter. pdf $>$. 


\section{Works cited}

Booth, Andrew. "Briefing Paper \#1. Facilitated Online Learning Interactive Opportunity (FOLIO): Evidence Based Librarianship (EBL)". 2003. National electronic Library for Health. 29 April 2003.

$<$ http://www.shef.ac.uk/scharr/eblib/briefi ng1.htm>.

---. "Australian Supermodel?--a Practical Example of Evidence-Based Library and Information Practice (EBLIP)." Health Information and Libraries Journal 23.1 (2006): 69-72.

---. "CriSTAL Online". 2003. 5 September 2005. $<$ http://www.shef.ac.uk/scharr/eblib/>.

---. "Exceeding Expectations: Achieving Professional Excellence by Getting Research into Practice." LIANZA 2000. Christchurch, New Zealand, 2000.

---. "Formulating Answerable Questions." Evidence-Based Practice for Information Professionals: A Handbook. Eds. Andrew Booth and Anne Brice. London: Facet, 2004. 61-70.

---. "Untangling the Web. Using Research in Practice." Health Information and Libraries Journal 21.1 (2004): 70-73.

---. "What Research Studies Do Practitioners Actually Find Useful?" Health Information and Libraries Journal 21.3 (2004): 197-200.

Booth, Andrew, and Anne Brice. "Appraising the Evidence." Evidence-Based Practice for Information Professionals: A Handbook. Eds. Andrew Booth and Anne Brice. London: Facet, 2004. 104-17.

Campbell, Nicole, et al. "Designing for the User: How to Test for Usability". 2001. 27 May 2005. $<$ http://www.vancouver.wsu.edu/fac/camp bell/usability/acrl/>.
Carter, Sharna, and Mary Grimmond.

"Rehabilitating the Stroke Collection." $\underline{\text { 3rd }}$ International Evidence Based

Librarianship Conference. Evolution of Evidence : Global Perspectives on Linking Research with Practice. Brisbane, Australia, 2005.

Clairmont, Michelle, Ruth Dickstein, and Vicki Mills. "Testing for Usability in the Design of a New Information Gateway". 30 May 2005.

$<$ http://www.library.arizona.edu/library/te ams/access9798/lft2paper.htm>.

Cotter, Lisa, et al. "Adding Spice to Our Library Intranet Site: A Recipe to Enhance Usability." 3rd International Evidence Based Librarianship Conference. Evolution of Evidence : Global Perspectives on Linking Research with Practice. Brisbane, Australia, 2005.

A Guide to the Project Management Body of Knowledge: PMBOK Guide. 3rd ed. Newtown Square, PA: Project Management Institute, Inc., 2004.

ISO 13407: Human-Centred Design Processes for Interactive Systems. Geneva: International Organization for Standardization, 1999.

Koyani, Sanjay J, Robert W Bailey, and Janice R Nall. Research-Based Web Design \& Usability Guidelines. Washington, D.C.: United States Department of Health and Human Services, 2003.

Krug, Steve. Don't Make Me Think! : A Common Sense Approach to Web Usability. Indianapolis, Ind.: New Riders, 2000.

MIT Libraries. "Web Site Usability Test". 1999. MIT Libraries. 27 May 2005. $<$ http://macfadden.mit.edu/webgroup/usa bility/results/index.html $>$.

Nielsen, Jakob. "Why You Only Need to Test with 5 Users". 2000. Jakob Nielsen's 
Alertbox. 20 June 2005.

$<$ http://www.useit.com/alertbox/20000319. $\underline{\mathrm{html}}>$.

Norlin, Elaina. Usability Testing for Library Websites: A Hands-on Guide / Elaina Norlin, CM! Winters. Chicago: American Library Association, 2002.

Pace, Andrew K. "Optimizing Library Web Services: A Usability Approach." Library Technology Reports 38.2 (2002): 2-81.

Pearce, Judith. "Testing the Usability of the NLA Web Site." National Library of Australia Gateways 51 (2001): 20-21.

Raward, Roslyn A. "A Report on the Development of a Usability Analysis Tool for the Evaluation of Library Websites."
Sydney, 2003. Information Online 2003: 11th Conference and Exhibition. (21-23 January 2003).

$<$ http://conferences.alia.org.au/online2003/ papers/raward.html>.

---. "A Study of Best Practice Design Guidelines and the Development of a Usability Analysis Tool for the Evaluation of Australian Academic Library Web Sites." Thesis (M.A.). University of Canberra, 2002.

Vaughn, Debbie, and Burton Callicott. "Broccoli Librarianship and Google-Bred Patrons, or What's Wrong with Usability Testing?" College \& Undergraduate Libraries 10.2 (2003): 1-18. 


\section{Appendix A}

\section{Post Test Discussion}

Thank you for your participation. Please take a moment to answer the following:

1. When you were completing the tasks, how did you feel (frustrated, confident, etc.)?

2. What do you like about the site?

3. If you were to change anything about the site, what would you change?

4. Any other comments?

5. What is your overall assessment of the site? Assign a mark out of 10. (1 is poor, 10 is great)

$\begin{array}{llllllllll}1 & 2 & 3 & 4 & 5 & 6 & 7 & 8 & 9 & 10\end{array}$




\section{Appendix B}

\section{Scenario-based Usability Test Tasks}

\section{Scenario 1}

You would like to request a change in the Gosford or Wyong Hospital Library's opening hours. How would you submit your suggestion via the Library's intranet site?

Objective: Can the client provide feedback to the Library? Can the client locate Library forms to request services?

\section{Scenario 2}

You have determined that the journal that has the article you need is not held in the Gosford nor Wyong Hospital Libraries, nor is it available online. Find an electronic form that you can use to request a photocopy of this article from another library.

Objective: Can the client request journal articles not directly available through $\mathrm{CCH}$ library Services? Can the client locate Library forms to request services?

\section{Scenario 3}

You need to talk to the librarian who liaises with the University of Newcastle. Locate their contact details on the Library's Intranet site.

Objective: Can the client contact the Library staff member best able to answer their inquiry?

\section{Scenario 4}

Its $10.00 \mathrm{pm}$ and you have just started your shift when you realise that your Library books are due today, but the Library is closed. Demonstrate how you would renew your books using the Library's intranet site.

Objective: Can the client manage their Library borrower account (such as renew books)?

\section{Scenario 5 (CCH staff only)}

Your manager/NUM has asked you to review a procedure commonly performed in your department/ward. Any changes you make must be evidence-based. You would like the librarian to do a search for the latest information on this topic. It is after hours and there is no phone help available. Show how you would submit a search request using the Library's intranet site?

Objective: Can the client locate Library forms to request services?

\section{Scenario 6}

- CCH staff : You would like to update your information-seeking skills and learn more about CIAP. Using the intranet site, how will you find out about training offered by the Library? 
- University :You would like to update your information-seeking skills and learn more about The University of Newcastle's online resources. Using the intranet site, how will you find out about training offered by the Library?

Objective: Can the client seek help to improve their information skills? Can the client contact the Library staff member best able to answer their inquiry?

\section{Scenario 7}

You are looking for a book on cardiac nursing and wonder whether the Gosford or Wyong Hospital Libraries have any. How would you find out using the Library's intranet site?

Objective: Can the client identify the catalogue, NEWCAT?

\section{Scenario 8}

You need to search MIMS and the print copies have all gone missing, so you have to look up the online version. Show us how you would access MIMS Online using the Library's intranet site?

Objective: Can the client access specific databases such as Medline, or MIMS? Can the client access CIAP or the University of Newcastle's online resources as appropriate?

\section{Scenario 9 (CCH staff only)}

Your colleague has told you there is a direct link on the Library's intranet site to the online edition of the European Respiratory Journal. View the current issue of this journal.

Objective: Can the client locate full-text journal articles, or the online edition of a journal?

\section{Scenario 10}

You need to read an article in the latest issue of The Lancet. Demonstrate how you would access the online version of The Lancet via the Library's intranet site?

Objective: Can the client locate full-text journal articles, or the online edition of a journal? Can the client access CIAP or the University of Newcastle's online resources as appropriate?

\section{Scenario 11}

- CCH staff :You have heard about CIAP and are keen to know more. Go to CIAP via the Library's intranet site so that you are able to browse the resources available.

- University : You have heard about The University of Newcastle's journal databases and are keen to know more. Go to the list of online databases provided by The University of Newcastle so that you are able to browse the resources available.

Objective: Can the client access CIAP or The University of Newcastle's online resources? 


\section{Scenario 12}

You need to search the health literature for information on a work/study related topic. The Library is not open to seek help. Demonstrate how you would begin.

Objective: Can the client select appropriate information resources to find required information?

\section{Scenario 13}

You would like to recommend that the Library purchase a particular book. Demonstrate how you would make this recommendation using the Library intranet site.

Objective: Can the client submit suggestions for new book purchases? Can the client locate Library forms to request services?

\section{Scenario 14}

You would like to know what is published in your favourite journal each month. You have heard table of contents alerts are available, but are unsure as to how to go about setting them up. Use the Library's intranet site to find help with this.

Objective: Can the client locate table of contents (TOC) and other current awareness services?

\section{Assistance Guidelines}

- If participant seeks help as they are lost, general advice would be to "Return to the Library Homepage and start again" and/or refer the participant back to the question.

- If participant is prompted to enter a password and seeks help - first, explain which password is required and encourage them to enter it if they know it. If they don't know it or don't have one, the test administrator should enter one, and the test monitor should note this as an issue. In the post-test interview, clear up any password issues.

- If the participant is obviously on the wrong track (due to misinterpretation of the question), the test administrator should clarify the scenario.

\section{Usability Test Sessions}

The 14 tasks have been divided into 2 separate tests. Each test will be administered to a group of participants with a similar profile. The 7 tasks in each test will be administered in random order to each participant. Tasks 5 and 9 will only be administered to CCH Staff.

\section{Test A}

Tasks 1, 2, 7, 9 ,11, 12, 14

\section{Test B}

Tasks $3,4, \underline{5}, 6,8,10,13$ 
The questions will be presented to the participants in the following order:

\section{Test A}

\begin{tabular}{|c|cccccccc|}
\hline Participant & Task Order & \multicolumn{7}{l|}{} \\
\hline A1 & 9 & 2 & 7 & 14 & 11 & 1 & 12 \\
\hline A2 & 14 & 12 & 7 & 11 & 9 & 1 & 2 \\
\hline A3 & 12 & 14 & 2 & 1 & 11 & 7 & 9 \\
\hline A4 & 7 & 12 & 14 & 9 & 1 & 11 & 2 \\
\hline A5 & 14 & 1 & 9 & 12 & 7 & 2 & 11 \\
\hline A6 & 12 & 7 & 1 & 14 & 2 & 9 & 11 \\
\hline A7 & 12 & 11 & 7 & 2 & 9 & 1 & 14 \\
\hline
\end{tabular}

\section{Test B}

\begin{tabular}{|c|ccccccc|}
\hline Participant & Task Order & \multicolumn{7}{c|}{} & & & \\
\hline B1 & 6 & 8 & 10 & 5 & 13 & 3 & 4 \\
\hline B2 & 3 & 10 & 6 & 8 & 5 & 13 & 4 \\
\hline B3 & 5 & 6 & 3 & 4 & 13 & 8 & 10 \\
\hline B4 & 3 & 4 & 10 & 5 & 13 & 8 & 6 \\
\hline B5 & 3 & 13 & 10 & 6 & 5 & 4 & 8 \\
\hline B6 & 3 & 5 & 13 & 10 & 4 & 6 & 8 \\
\hline B7 & 13 & 3 & 5 & 10 & 8 & 6 & 4 \\
\hline
\end{tabular}




\section{Appendix C}

\section{Participant Profile Questionnaire}

Tester number :

Test version : $\square \mathrm{A}$

Test date/time :

$$
\square B
$$

\section{Personal profile}

Domain : $\begin{array}{ll} & \square \text { allied health } \\ & \square \text { medicine } \\ & \square \text { nursing } \\ & \square \text { student } \\ & \square \text { other }\end{array}$

Which organisation's online resources are you eligible to access?

$\square$ Central Coast Health

The University of Newcastle

Is English your first language?

\section{$\square$ Yes}

\section{Computer experience}

$\square$ No

How often do you use a computer (at home or at work)?

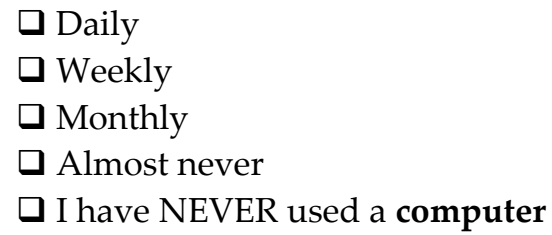

How often do you use the hospital's intranet?

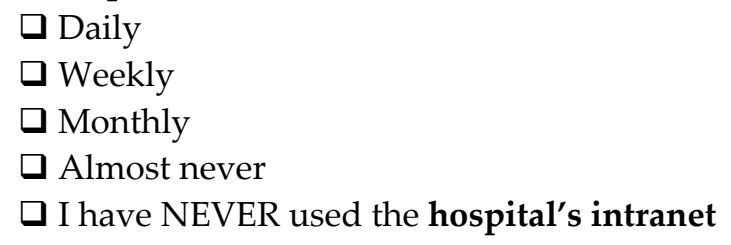

How often do you use the CCH Library Services' intranet site?

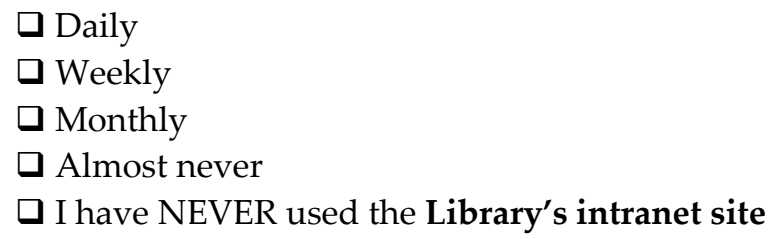

Do you agree to an audio-recording of the test session being made?

$$
\begin{aligned}
& \square \text { Yes } \\
& \square \text { No }
\end{aligned}
$$




\section{Appendix D}

Usability Test Recording Sheet - Recorder (sample)

\section{SCENARIO 1}

You would like to request a change in the Gosford or Wyong Hospital Library's opening hours. How would you submit your suggestion via the Library's intranet site?

Objective: Can the client provide feedback to the Library? Can the client locate Library forms to request services?

Criteria for success: Ask A Question form is located, or appropriate contact details are identified.

Preferred path: Ask A Question LOGO/LINK

Or

Contact Us I identify the Library Manager, General Inquiries, or Ask A Question form

Time allowed: 3 minutes (maximum)

\section{BROWSING}

Note path taken \& navigation tools used:

Top navigation bar

$\square$ Left navigation bar

$\square$ QuickLinks

$\square \log o s$

\section{SEARCH TOOL}

Was the search $\square$ Yes Search terms used:

tool used? $\quad \square$ No

Did the search tool $\square$ Yes Comments:

provide the $\square$ No

answer?

\section{DESCRIBE ISSUES/PROBLEMS:}




\section{Appendix E}

Usability Test Recording Sheet - Administrator (sample)

\section{SCENARIO 1}

You would like to request a change in the Gosford or Wyong Hospital Library's opening hours. How would you submit your suggestion via the Library's intranet site?

Objective: Can the client provide feedback to the Library? Can the client locate Library forms to request services?

Criteria for success: Ask A Question form is located, or appropriate contact details are identified.

Preferred path: Ask A Question LOGO/LINK

Or

Contact Us I identify the Library Manager, General Inquiries, or Ask A Question form

Time allowed: 3 minutes (maximum)

CLICKS

\section{COMMENTS}

\section{PASSWORD ISSUES}

$\square$ Internet

$\square$ CIAP

$\square$ Database

$\square$ NEWCAT PIN

Comments: 


\section{SUMMARY}

Successfully completed within time allowed?

Number of clicks:

$\square$ Yes

$\square$ No 


\section{Appendix F}

Usability Test Recording Sheet - Summary (sample)

\section{SCENARIO 1}

You would like to request a change in the Gosford or Wyong Hospital Library's opening hours. How would you submit your suggestion via the Library's intranet site?

Objective: Can the client provide feedback to the Library? Can the client locate Library forms to request services?

Criteria for success: Ask A Question form is located, or appropriate contact details are identified.

Preferred path: Ask A Question LOGO/LINK

Or

Contact Us I identify the Library Manager, General Inquiries, or Ask A Question form

Time allowed: 3 minutes (maximum)

\section{SUMMARY}

Successfully completed within time allowed? $\square$ Yes $\square$ No

Successful via expected path

Successful via unusual path

$\square$ Error made, though recovered

$\checkmark$ Error made, did not recover

\section{Navigation}

Top navigation bar

$\square$ Left navigation bar

QuickLinks

$\square \operatorname{Logos}$

Number of clicks:

\section{Level of concern}

$\square$ Minor

Architecture

Major

Content

- missing.

- out-of-date / erroneous...

Navigation

- CCH Intranet site.

- Library Services site......

Presentation

Search tool......

Terminology.....

User support / help. $\square$ Major $\square$ Minor

$\square$ Major $\square$ Minor

$\square$ Major

Minor

a Major a Minor

anajor $\square$ Minor

Major $\square$ Minor

a Major $\square$ Minor

a Major $\square$ Minor

\section{Comment}
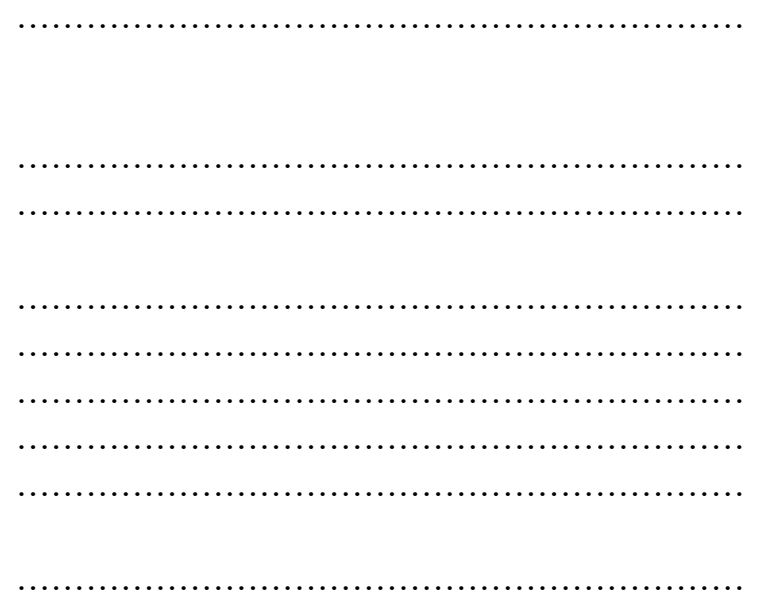
PASSWORD ISSUES

$\square$ Internet

$\square$ CIAP

$\square$ Database

$\square$ NEWCAT PIN 